\title{
Compósitos de PVC rígido e fibras de bananeira: Efeito do tratamento da fibra
}

\author{
Banana Fibers and rigid PVC composites: \\ Effect of fiber treatment
}

\author{
D. Becker ${ }^{1}$, A. C. Kleinschmidt ${ }^{2}$, P. S. Balzer ${ }^{2}$
}

\author{
${ }^{1}$ Centro de Ciências Tecnológicas - CCT/UDESC - Joinville SC \\ e-mail: danibkr@gmail.com \\ ${ }^{2}$ Centro Universitário Tupy - UNISOCIESC - Joinville - SC \\ e-mail: annynha_eu@yahoo.com.br; palova@sociesc.org.br
}

\begin{abstract}
RESUMO
O interesse de compósitos de fibras naturais com polímeros termoplásticos vem crescendo a cada ano. As fibras naturais apresentam vantagens como baixa massa específica, baixa abrasividade, baixo custo, são biodegradáveis e autossustentáveis, pois são de origem natural e de fonte renovável. Dentre as resinas termoplásticas viáveis para o emprego de fibras de bananeira destaca-se a resina de poli (cloreto de vinila) - PVC por sua versatilidade em relação a sua formulação, pois há a necessidade da incorporação de aditivos durante o seu processamento, tornando-a adaptável a múltiplas aplicações. O objetivo do presente trabalho foi estudar a influência do tipo de tratamento das fibras de bananeira (FB) nas propriedades do PVC rígido (PVCr). Propriedades mecânicas, estabilidade térmica e absorção de água dos compósitos PVC/FB foram avaliados em relação ao efeito dos tratamentos alcalino, com anidrido maleico e acetilação das fibras de bananeiras. Os compósitos foram obtidos em misturador aberto de dois rolos seguido de injeção dos corpos de provas. Os resultados indicam que o tratamento com anidrido maleico e a acetilação apresentam melhor resistência ao impacto e menor absorção de água do que o tratamento alcalino. As propriedades térmicas não apresentaram alterações significativas com a adição de fibras de bananeiras tratadas e não tratadas.
\end{abstract}

Palavras-chave: poli (cloreto de vinila); fibras de bananeira; tratamento superficial.

\section{ABSTRACT}

The interest in natural fiber composites with thermoplastic polymers is growing every year. Natural fibers have advantages such as low density, low abrasion, low cost, are biodegradable and self-sustainable, since they are natural and renewable source. Among the thermoplastic resins viable for employment fiber banana stands out poly (vinyl chloride) - PVC for its versatility compared to its formulation, because there is the need to incorporate additives during processing, making adaptable to multiple applications. The objective of this work was to study the influence of type of banana fibers (FB) treatment in the properties of rigid poly (vinyl chloride) (PVC). Mechanical properties, thermal stability and water absorption of composite PVC/FB were evalueted for the effect of alkaline treatments, with maleic anhydride and acetylation of banana fibers. The composites were obtained in two-roll open mixer followed by injection of test samples. The results indicate that treatment with maleic anhydride and acetylation exhibit better impact resistance and lower water absorption than the alkaline treatment. The thermal properties did not change significantly with the addition of banana fibers treated and untreated.

Keywords: poly (vinyl chloride); banana fibers; superficial treatment.

\section{INTRODUÇÃO}

O poli (cloreto de vinila) - PVC é um termoplástico de uso comum com uma grande versatilidade de aplicações devido ao emprego de aditivos na formulação do mesmo, o que possibilita a alteração de suas propriedades térmicas, mecânicas e morfológicas. As propriedades do PVC podem variar de um polímero extremamente flexível a um polímero extremamente rígido $[\underline{1}, \underline{2}]$.

Atualmente, a constante busca pela utilização de fibras para reforço de materiais poliméricos tem en- 
contrado diversas tendências, entre elas as fibras naturais. Estas são muito utilizadas como reforço, pois se trata de materiais biodegradáveis, provenientes de fontes renováveis. Também é de baixo custo, baixa massa específica e não são abrasivas, evitando assim maior desgaste do ferramental e facilidade no processo de moldagem, podendo em alguns casos substituir as fibras sintéticas em compósitos poliméricos [프, $\underline{5}]$.

Hoje já são utilizadas fibras de sisal, bambu, bagaço de cana-de-açúcar, curauá, madeira, fibra de bananeira, entre outras. O emprego de fibras naturais como reforço em matriz polimérica, tanto utilizando materiais termofixos como as resinas de poliésteres, epóxis e fenólicas como termoplásticos, principalmente o polipropileno (PP), polietileno (PE) [ $[\underline{6}, \underline{7}]$ e poucos estudos utilizam o poli (cloreto de vinila) (PVC) flexível

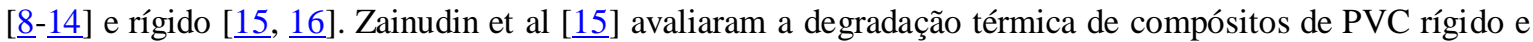
fibra de bananeira, e foi observado que a adição das fibras não altera o processo de degradação térmica do PVC. Nos estudos realizados por Balzer e colaboradores [16], observou-se que a adição da fibra de bananeira mostrou-se viável na formação de compósitos de PVC rígido, apresentando um aumento na resistência à tração, bem como uma discreta redução da massa específica do compósito resultante, potencializando a obtenção de componentes com melhor desempenho mecânico e menor peso.

A principal desvantagem da adição de fibras naturais em matrizes poliméricas é a baixa adesão interfacial entre a fibra e matriz. Se não ocorrer o tratamento da fibra ou a adição de agente compatibilizante, a fraca adesão entre as fases resulta em perda nas propriedades mecânicas [13]. Com objetivo de melhorar a compatibilização entre a fibra e a matriz polimérica, métodos como, modificação da superfície da fibra a partir de tratamentos químicos ou adição de agente compatibilizantes são utilizados [4, 17-19]. Por exemplo, Saini et al [12] estudaram o efeito do tratamento alcalino do bagaço da cana-de-açúcar nas propriedades do compósito de matriz de PVC flexível. Após o tratamento, os autores observaram uma diminuição na absorção de água e um aumento da resistência ao impacto e no módulo de Young. Djidjelli e colaboradores [13] estudaram compósitos de PVC flexível/fibras de sisal tratadas com anidrido maleico e observaram que o tratamento melhorou a compatibilidade do PVC com fibra, diminuindo a absorção de água e melhorando as propriedades mecânicas.

Considerando que a maioria dos trabalhos que estudam compósitos com fibras naturais em matrizes de PVC utilizam PVC flexível, este estudo tem como objetivo estudar o efeito das fibras de bananeiras modificadas por tratamento alcalino, acetilação e anidrido maleico nas propriedades dos compósitos de PVC rígido.

\section{MATERIAIS E MÉTODOS}

\subsection{Materiais}

Os compósitos utilizados neste estudo são baseados no poli (cloreto de vinila) (PVC), fornecido pela Braskem, com nome comercial Norvic ${ }^{\circledR}$ SP 100 com valor K de 65 e fibras de bananeiras (FB), obtido da Empresa de Pesquisa Agropecuária e Extensão rural de Santa Catarina (EPAGRI). A Tabela 1 apresenta a formulação básica para todos os compósitos de PVC rígido/FB. As quantidades de cada componente foram expressas em partes por cem de resina de PVC (pcr) exceto a $\mathrm{FB}$, que foi utilizada em porcentagem volumétrica (\%) do volume total do PVC. Para obtenção dos compósitos, as fibras foram cortadas manualmente em $20 \mathrm{~mm}$ de comprimento.

Tabela 1: Formulação utilizada nos compósitos de PVC/FB.

\begin{tabular}{l|c}
\hline \multicolumn{1}{c|}{ Material } & Concentração (pcr/*\% em volume) \\
\hline PVC (Norvic ${ }^{\circledR}$ SP 1000) & 100,0 \\
Naftomix xc8101 & 3,6 \\
Comarlub 0,5 & 0,2 \\
Calcium stearate & 0,5 \\
K-12“O”(CA120BR) & 0,5 \\
Fibras de bananeira* & 10,0 \\
\hline
\end{tabular}




\subsection{Modificação das Fibras}

\subsubsection{Tratamento alcalino (mercerização)}

O procedimento experimental foi baseado no estudo de Carvalho e colaboradores [20]. As fibras foram imersas em uma solução aquosa de hidróxido de sódio $5 \%$ e mantidas por $4 \mathrm{~h}$. Ao final do tratamento foram neutralizadas com ácido sulfúrico e em seguida lavadas em água corrente abundante. As fibras foram secas em estufa á vácuo a $70^{\circ} \mathrm{C}$ até apresentar massa constante.

\subsubsection{Acetilação}

As fibras foram imersas numa solução de ácido acético glacial e anidrido acético 1:1 na presença de ácido nítrico concentrado como catalisador. A mistura foi continuamente aquecida até o ponto de ebulição e mantida nesta temperatura por 4h. Após o tratamento, as fibras foram deixadas em água por 15h e lavadas várias vezes com água destilada até a neutralização do $\mathrm{pH}$. As fibras foram secas em estufa a vácuo a $70^{\circ} \mathrm{C}$ até massa constante. Este procedimento foi adaptado do trabalho de Zafeiropoulos [21].

\subsubsection{Anidrido maleico}

O procedimento experimental utilizado neste estudo foi baseado no apresentado por Djidjelli e colaboradores [8]. A reação foi realizada sob refluxo a $140^{\circ} \mathrm{C}$ por $2 \mathrm{~h}$ numa solução da fibra de bananeira em xileno contendo anidrido maleico $(5 \% \mathrm{~m} / \mathrm{m})$ e peróxido de benzoila $(0,5 \% \mathrm{~m} / \mathrm{m})$. Após este tempo as fibras foram retiradas da solução e lavadas com água destilada para remover o material não reagido. As fibras foram secas em estufa á vácuo a $70^{\circ} \mathrm{C}$ até massa constante.

\subsection{Obtenção das misturas}

A adição das fibras para obtenção dos compósitos de PVC foi de forma aleatória, utilizando um misturador aberto de dois cilindros com disposição horizontal, à temperatura de $165^{\circ} \mathrm{C}$ e $153^{\circ} \mathrm{C}$, respectivamente. Os compósitos foram secos em estufa a vácuo a $70^{\circ} \mathrm{C}$ por $24 \mathrm{~h}$ e os corpos de provas para o ensaio de tração e impacto foram injetados em uma injetora Sandreto Micro 65. Foi utilizado um perfil de temperatura variando de 145 a $185^{\circ} \mathrm{C}$, a pressão de recalque de 300 bar e a temperatura do molde de $25^{\circ} \mathrm{C}$ com tempo de resfriamento de $20 \mathrm{~s}$.

\subsection{Análise Termogravimétrica}

As matérias-primas utilizadas neste trabalho e os compósitos foram analisados através de termogravimetria (TGA) para avaliação da estabilidade térmica. As curvas de TGA foram obtidas utilizando um equipamento da TA Instruments TG Q200, em atmosfera de nitrogênio com uma taxa de aquecimento de $10^{\circ} \mathrm{C} / \mathrm{min}$, da temperatura ambiente até $600^{\circ} \mathrm{C}$. Para a determinação da temperatura na qual a velocidade de perda de massa é máxima $\left(\mathrm{T}_{\text {pico }}\right)$ foi utilizada a primeira derivada do termograma (DrTGA).

\subsection{Propriedades Mecânicas}

O ensaio de resistência ao impacto Charpy foi realizado no equipamento Emic, com martelo de 0,5 J, seguindo a norma ISO 179. O ensaio de resistência à tração foi realizado na Máquina Universal de Ensaios Emic DL 2000, seguindo a norma ISO 527, com velocidade de ensaio de $50 \mathrm{~mm} / \mathrm{min}$.

\subsection{Absorção de água}

Os ensaios de absorção de água foram realizados com base na norma ASTM D 570-99. Para cada compósito, cinco amostras de $10 \times 10 \mathrm{~mm}^{2}$ foram cortadas dos corpos de provas de tração. As amostras foram pesadas $\left(\mathrm{w}_{\mathrm{o}}\right)$ após secas em estufa a vácuo, em temperatura de $50^{\circ} \mathrm{C}$ por $24 \mathrm{~h}$. Para medir a absorção de água do compósito, todas as amostras foram imersas em água destilada a temperatura ambiente por $24 \mathrm{~h}$ e então pesadas $\left(\mathrm{w}_{\mathrm{f}}\right)$. A quantidade de água absorvida (PWA) foi calculada usando a Equação 1. 


$$
\operatorname{PWA}=\frac{\left(\mathrm{w}_{\mathrm{f}}-\mathrm{w}_{\mathrm{o}}\right)}{\mathrm{w}_{\mathrm{o}}} \mathrm{x} 100
$$

\subsection{Microscopia Eletrônica de Varredura}

Alterações na morfologia da superfície de fratura do ensaio de tração dos compósitos de PVC com fibras de bananeira foram observadas no microscópio eletrônico de varredura (MEV) Zeiss DSM, sendo que as amostras foram recobertas com fina camada de ouro.

\section{RESULTADOS}

A absorção de água é um parâmetro importante quando se trabalha com fibras naturais, pois a alta higroscopicidade reduz as propriedades mecânicas (de tração, por exemplo) do material e alterações das dimensões [14]. A Figura 1 ilustra a quantidade de água absorvida pelo PVC e os compósitos de PVC/FB com diferentes tratamentos superficiais. A adição de fibras de bananeira não tratadas na matriz de PVC aumenta a taxa de absorção de água devido a grande quantidade de grupos hidroxilas na celulose da fibra natural, propiciando uma característica hidrofílica à matriz hidrofóbica do PVC [22]. Nos compósitos com fibras de bananeira tratada, a quantidade de água absorvida diminuiu após os tratamentos das fibras através de reações de acetilação e com anidrido maleico. De acordo com Li e colaboradores [3] a acetilação pode reduzir a natureza higroscópica das fibras naturais, devido a mesma substituir os grupos hidroxilas presentes na superficie da fibra por grupos acetil, modificando as propriedades destas fibras tornando-as mais hidrofóbicas. O tratamento com anidrido maleico também pode reduzir a absorção de água das fibras de bananeiras por que os grupos hidroxilas hidrofílicos presentes nas fibras reagem com o grupamento do anidrido maleico para formar ligações ésteres reduzindo a capacidade de absorção de água da fibra [23]. Djidjelli e colaboradores [ㅁ] também observaram um decréscimo na absorção de água em compósitos de PVC e fibras de sisal tratadas com anidrido maleico.

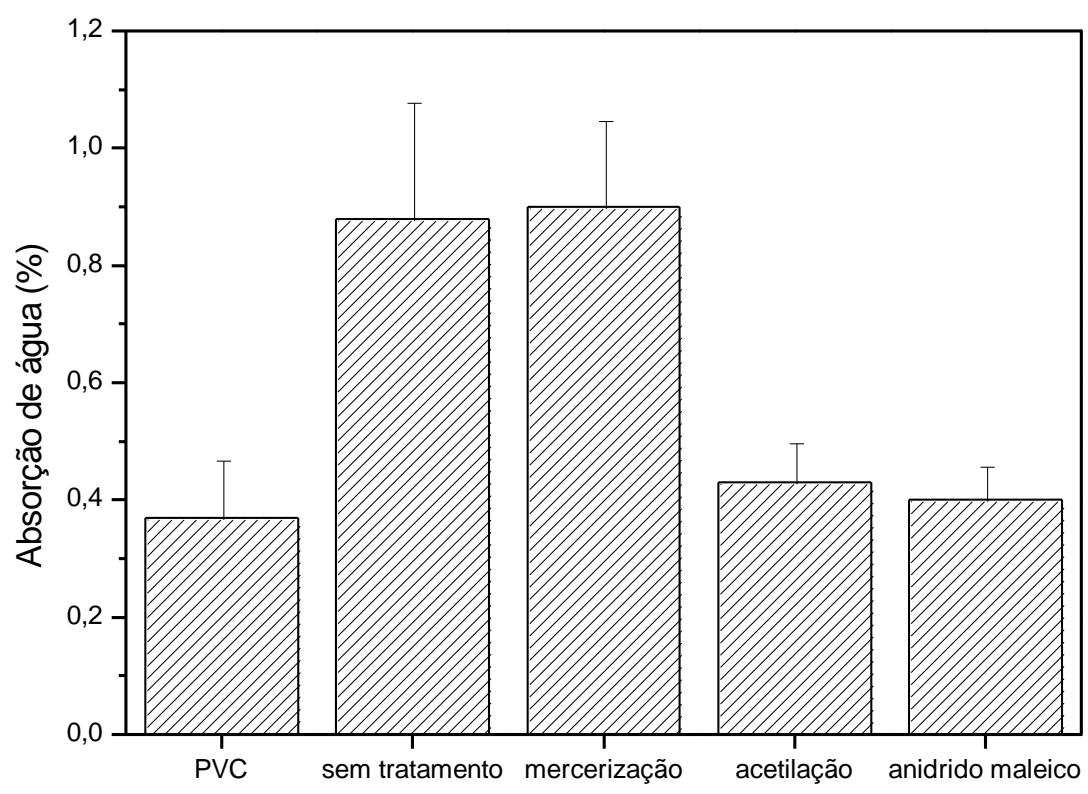

Figura 1: Efeito do tratamento das fibras de bananeira na absorção de água nos compósitos de PVC/FB.

As curvas da análise de termogravimetria (TG) e as correspondentes primeira derivada (DrTG) dos compósitos de PVC/FB com diferentes tratamentos são apresentadas na Figura 2 e os resultados são exemplificados na Tabela 2. Pode-se notar que a adição de fibras tratadas e não tratadas na matriz de PVC não alteram significativamente o comportamento térmico quando comparado com o PVC puro predominando o mecanismo de degradação do PVC. Na curva de TG do PVC observam-se dois estágios de perda de massa em função da temperatura, sendo dois estágios bem definidos. O primeiro estágio (patamar) tem início na temperatura próxima daquela utilizada no processamento em que ocorre a formação do $\mathrm{HCl}$ com formação de dienos, o que acaba catalisando o processo de degradação. Já o outro estágio de degradação pode estar relacio- 
nado com a degradação das insaturações $(\mathrm{C}=\mathrm{C})$ formadas com a eliminação do $\mathrm{HCl}$ no primeiro estágio de degradação [1]. A temperatura de perda de $5 \%$ de massa $\left(\mathrm{T}_{5 \%}\right)$ e as temperaturas de pico do PVC puro e dos compósitos também não apresentaram diferenças significativas. Martins et al [10] também observaram este comportamento em compósitos de PVC/fibra de sisal e relataram estar relacionado com o fato de que as fibras não introduzem um processo adicional de degradação devido a fraca interação fibra/matriz.

Tabela 2: Temperatura de degradação dos compósitos de PVC/FB das curvas de TG e DTG.

\begin{tabular}{l|ccc}
\hline Materiais & $\mathrm{T}_{5 \%}\left({ }^{\circ} \mathrm{C}\right)$ & $\mathrm{T}_{\text {pico } 1}\left({ }^{\circ} \mathrm{C}\right)$ & $\mathrm{T}_{\text {pico } 2}\left({ }^{\circ} \mathrm{C}\right)$ \\
\hline PVC puro & 257 & 286 & 467 \\
PVC/FB não tratada & 258 & 286 & 463 \\
PVC/FB mercerizadas & 259 & 288 & 463 \\
PVC/FB acetiladas & 255 & 285 & 497 \\
PVC/FB com anidrido maleico & 260 & 287 & 462 \\
\hline
\end{tabular}

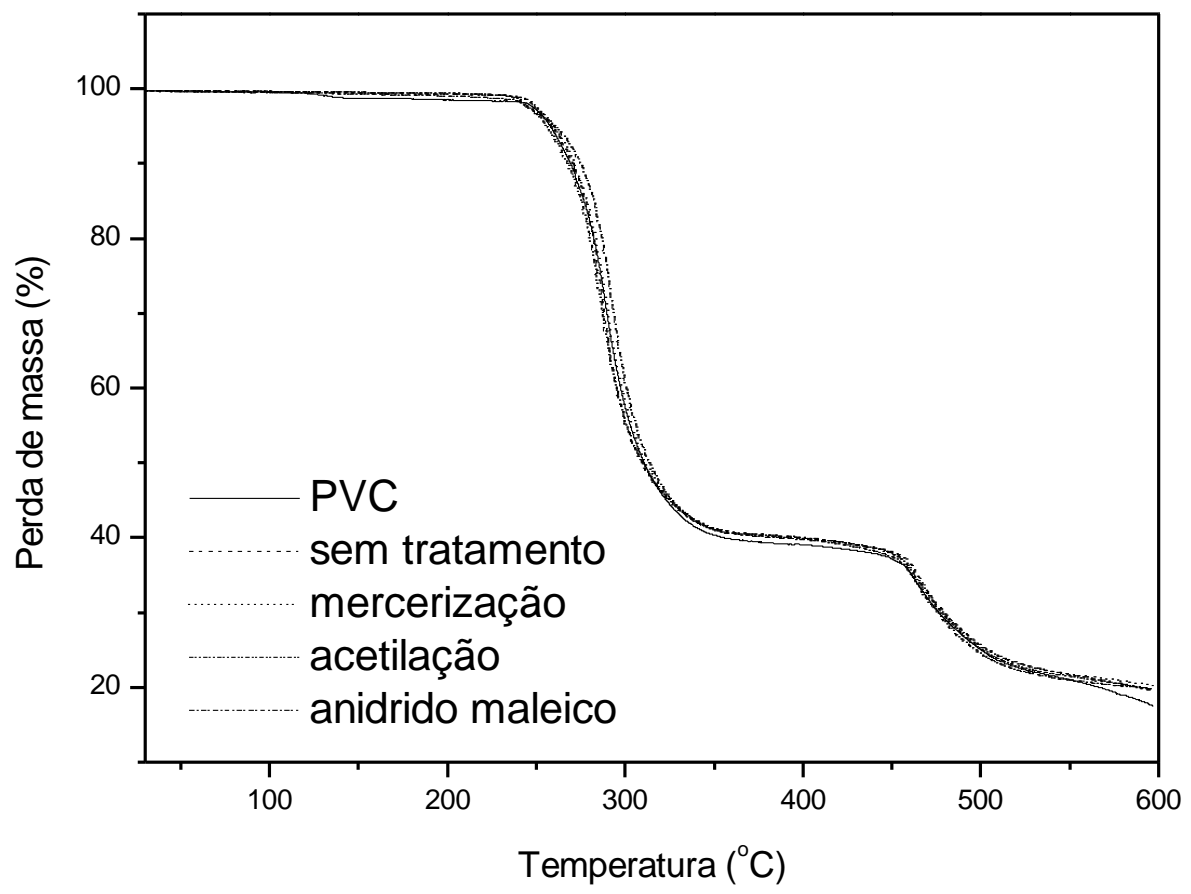

Figura 2: Curvas de termogravimetria dos compósitos PVC/FB com e sem tratamento

As propriedades mecânicas de PVC puro e os compósitos com fibras não tratadas e tratadas são apresentadas na Tabela 3. A adição da fibra de bananeira aumenta a resistência ao impacto do PVC, comportamento observado por Balzer e colaboradores [15]. A acetilação e o tratamento com anidrido maleico não modificam o comportamento do compósito. Entretanto, o tratamento de mercerização das fibras de bananeira levam a um decréscimo da resistência ao impacto, o que pode estar relacionado com o excesso de delignificação da fibra natural durante o tratamento, resultando no enfraquecimento das mesmas []].

Em termos de propriedades de tração, foi observado um decréscimo na resistência à tração independente do tratamento. Este comportamento pode estar relacionado com a falta de adesão entre matriz-fibra, conforme observado nas micrografias apresentadas da Figura 3. Djidjelli e colaboradores [8] também relacionaram este decréscimo à baixa dispersão das fibras na matriz e baixa adesão entre as fibras e a matriz. Esse comportamento também observado por Sombatsompop et al [24] em compósitos de PVC/serragem e Martins e colaboradores [10] para PVC e fibras de sisal. Também não foi observado uma alteração significativa do módulo de Young com adição da fibra de bananeira não tratada e tratada. Este comportamento pode estar relacionado com o fato do PVC utilizado ser rígido, pois os autores que observaram um aumento significativo do módulo de Young em compósitos de PVC com fibras naturais utilizaram matrizes plastificadas e os 
valores máximos alcançados nos compósitos obtidos são próximos aos observados neste trabalho [ㅁ-11] com PVC rígido.

Tabela 3: Efeito do tratamento das fibras de bananeira nas propriedades mecânicas dos compósitos de PVC/FB.

\begin{tabular}{c|ccc}
\hline Materiais & $\begin{array}{c}\text { Resistência ao impacto } \\
\left(\mathrm{kJ} / \mathrm{m}^{2}\right)\end{array}$ & $\begin{array}{c}\text { Resistência à Tração } \\
(\mathrm{MPa})\end{array}$ & Modulo de Young $(\mathrm{GPa})$ \\
\hline PVC & $3,8 \pm 0,1$ & $63,0 \pm 0,7$ & $3,2 \pm 0,3$ \\
Não tratado & $5,3 \pm 0,4$ & $50,5 \pm 2,3$ & $3,9 \pm 0,3$ \\
Mercerização & $4,1 \pm 0,3$ & $50,1 \pm 1,7$ & $3,3 \pm 0,8$ \\
Acetilação & $5,1 \pm 0,5$ & $52,2 \pm 1,4$ & $2,7 \pm 0,1$ \\
Anidrido maleico & $5,8 \pm 0,9$ & $50,2 \pm 2,0$ & $2,8 \pm 0,2$ \\
\hline
\end{tabular}




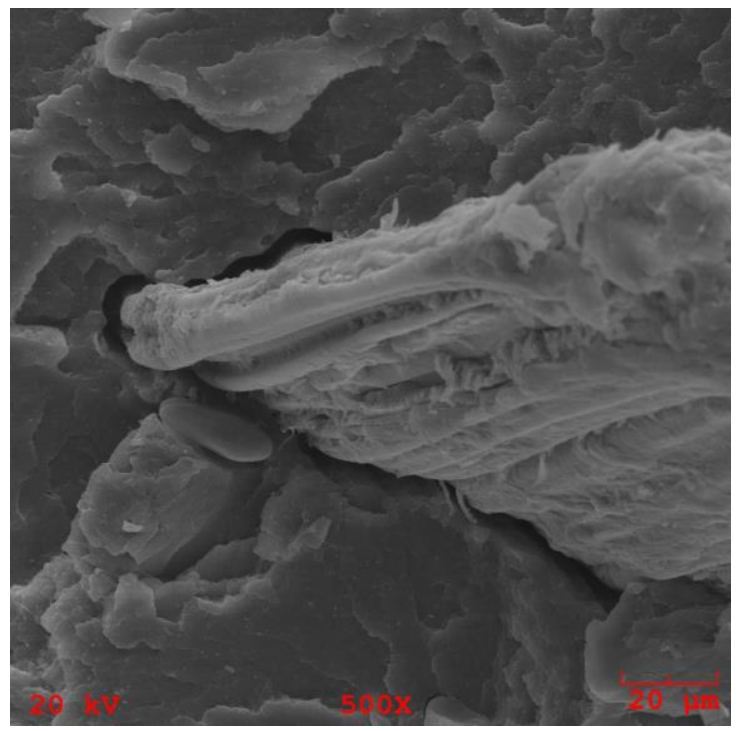

(a)

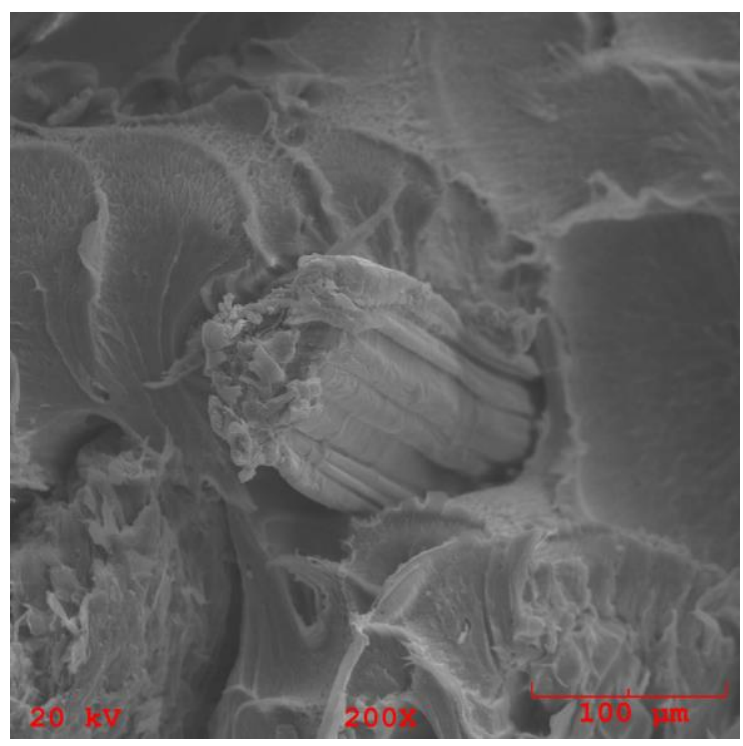

(c)

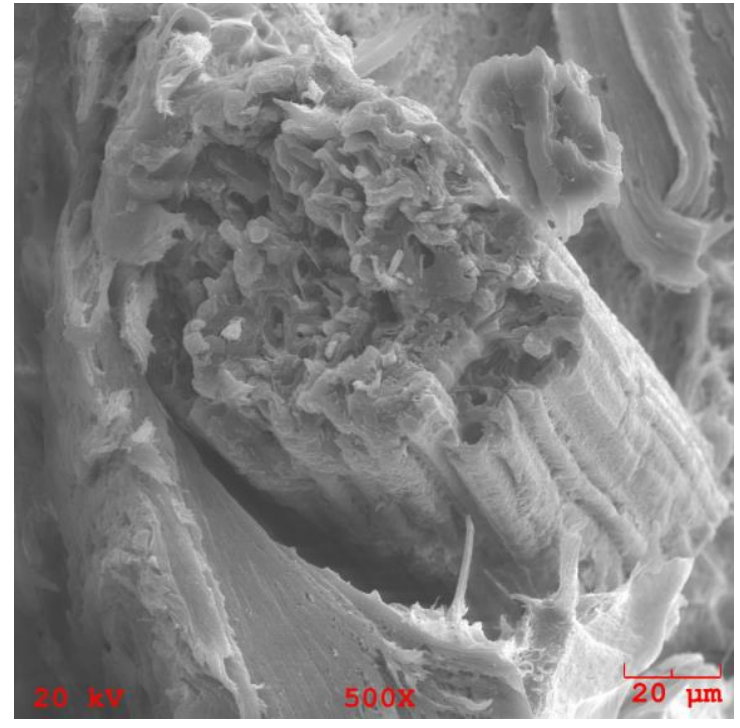

(b)

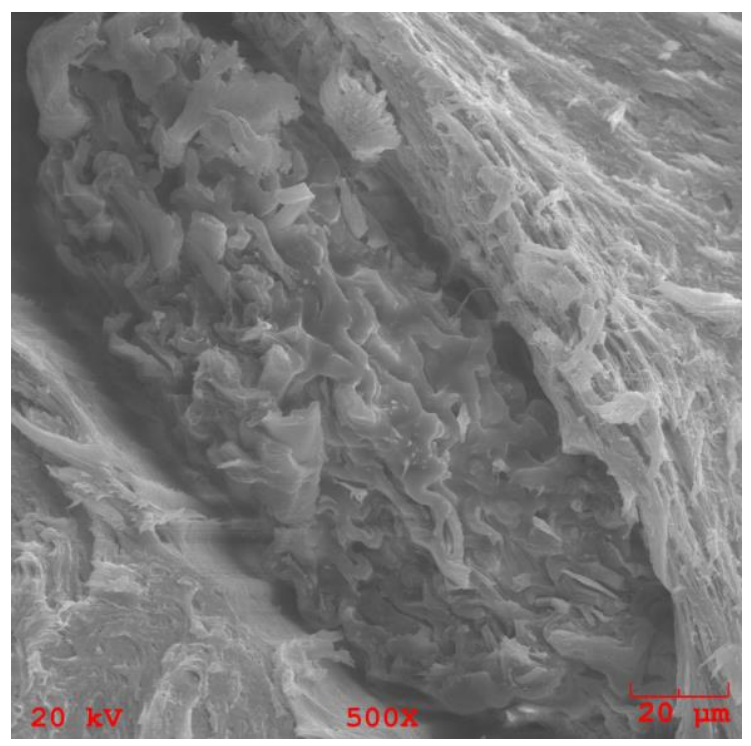

(d)

Figura 3: Micrografias obtidas por MEV dos compósitos de PVC com fibras de bananeira: (a) não tratada; e tratada com (b) mercerização, (c) acetilação, (d) anidrido maleico.

\section{CONCLUSÕES}

Os efeitos do tipo de tratamento das fibras de bananeira foram avaliados em relação à absorção de água, propriedades térmicas e mecânicas dos compósitos de PVC rígido. Os resultados sugerem que o tratamento químico da fibra não interfere diretamente em todas as propriedades analisadas e que o tipo de tratamento escolhido pode não alterar as propriedades.

As fibras de bananeira tratadas por mercerização, não apresentaram resultados significativos e absorveu água como as fibras não tratadas. Já os compósitos tratados com a acetilação e o anidrido maleico apresentaram maior resistência ao impacto, menor absorção de água e maior afinidade com a matriz polimérica do que o compósito com a fibras não tratadas ou tratadas por mercerização. 
Assim, pode-se observar que o tipo de tratamento escolhido pode influenciar nas propriedades do compósito de forma positiva para algumas propriedades como a resistência ao impacto, como de forma negativa (como absorção de água) ou ainda não apresentar alteração significativa, como a resistência á tração.

\section{AGRADECIMENTOS}

Os autores agradecem a Braskem pela doação do material, FAPESC e Braskem pelo apoio financeiro através do projeto CON04316/2008-8 e CNPq pela bolsa de apoio técnico através do projeto n502259/2008-6 e a Unipol pelas misturas do PVC.

\section{BIBLIOGRAFIA}

[1] RODOLFO, A.J., NUNES, L.R., ORMANJI, W. Tecnologia do PVC; ProEditores/Braskem, São Paulo, 2006.

[2] BRYDSON, J. A. Plastics materials, 5 ed., Oxford: Butterworth-Heinemann, 1995.

[3] LI, X.; TABIL, L.G.; PANIGRANI, S., "Chemical treatments of natural fiber for use in natural fiberreinforced composites: A review”, Journal Polymer Environmental. v.15, pp.25-33, Jan. 2007.

[4] POTHAN L.A, THOMAS, S. "Polarity parameters and dynamic mechanical behaviour of chemically modified banana fiber reinforced polyester composites", Composites Science and Technology, v. 63, pp.1231-1240, Fev. 2003.

[5] ISHIZAKI, M.H., VISCONTE, L.L.Y., FURTADO, C.R.G., et al., "Caracterização mecânica e morfológica de compósitos de polipropileno e fibras de coco verde: Influência do teor de fibras e das condições de mistura ", Polímeros: Ciência e Tecnologia, v.16, n. 03, pp.182-186, 2006.

[6] SATYANARAYANA, K.G., GUIMARÃES, J.L., WYPYCH, F. "Studies on lignocellulosic fibers of Brazil. Part I : Source, production, morfology, properties and applications", Composites: Part A: applied science and manufacturing, v. 38, pp.1694-1709, 2007.

[7] HOLBERY, J., HOUSTON, D. "Natural-fiber-reinforced polymer composites in automotive applications", Journal of the minerals, metals and materials society, v.58, pp.80-86, 2006.

[8] DJIDJELLI, H., BOUKERROU, A., FOUNAS, R., et al., "Preparation and characterization of poly (vinyl chloride)/virgin and treated sisla fiber composites", Journal of Applied Polymer Science. v. 103, pp.36303636, 2007.

[9] CRESPO, J.E., SÁNCHEZ, L., GARCÍA, D., et al., "Study of the mechanical and morphological properties of plasticized PVC composites containing rice husk fillers", Journal of reinforced plastics and composites, v. 27, n. 3, pp. 229-243, 2008.

[10] MARTINS, G.S., IOZZI, M.A., MARTINS, M.A., et al., "Caracterização mecânica e térmica de compósitos de poli (cloreto de vinila) reforçados com fibras de sisal”, Polímeros: Ciência e Tecnologia, v. 14, n. 5, pp. 326-333, 2004.

[11] MATUANA, L.M, WOODHAMS, R.T., BALATINECZ, J.J., et al., "Influence of interfacial interactions on the properties of PVC/cellulosic fiber composites", Polymer composites, v. 19, n. 4, Ago. 1998.

[12] XU, Y., WU, Q., LEI, Y., et al., "Natural fiber reinforced poly (vinyl chloride) composites: Effect of fiber type and impact modifier", Journal Polymer Environmental, v. 16, pp.250-257, 2008.

[13] ZHENG, Y-T, CAO, D-R, WANG, D-S, et al., "Study on the interface modification of bagasse fibre and the mechanical properties of its composite with PVC", Composites part A: applied science and manufacturing, v. 38, pp. 20-25, 2007.

[14] SAINI, G., NARULA, A.K., CHOURDHARDY, V., et al., "Effect of particle size and alkali treatment of sugarcane bagasse in thermal, mechanical and morphological properties of PVC-bagasse composites", Journal of reinforced plastic and composites, v. 28, n. 5, pp. 731-740, 2010.

[15] BALZER, P.S., VICENTE, L.L., BECKER, D., et al., "Estudos das propriedades Mecânicas de um composto de PVC modificado com Fibras de Bananeira", Polímeros: Ciência de Tecnologia, v. 17, pp.1-4, 2007.

[16] ZAINUDIN, E.S., SAPUAN, S.M., ABDAN, K., et al., "Thermal degradation of banana pseudo-stem filled unplasticized polyvinyl chloride (UPVC) composites”, Materials and Desing, v. 30, pp. 557-562, 2009.

[17] RAZERA, I.A. Fibras lignocelulósicas como agente de reforço de compósitos de matriz fenólica e lignofenólica, Tese de doutorado, USP, São Carlos, SP, Brasil, 2006. 
[18] GASSAN J. "A study of fibre and interface parameters affecting the fatigue behavior of natural fibre composites", Composites part A: applied science and manufacturing, v. 33, pp. 369-374, 2002.

[19] KEENER, T.J., STUART, R.K., BROWN, T.K. "Maleated coupling agents for natural fibre composites". Composites part A: applied science and manufacturing, v. 35, pp. 357-362, 2004.

[20] CARVALHO, S.B., BECKER, D., BALZER, P.S. "Compósitos de poli (cloreto de vinila) e fibra de bananeira: Estudo da influência do tratamento alcalino da fibra de bananeira nas propriedades do compósito" In: 10 Congresso Brasileiro de Polímeros, Foz de Iguaçu, out. 2009.

[21] ZAFEIROPOULOS, N.E., WILLIAMS, D.R., BAILLIE, C.A., et al.,"Engineering and Characterisation of the Interface in Flax fibre/Polypropylene Composite materials Part II: The Effect of Surface Treatments on the Interface", Composites part A: applied science and manufacturing, v. 33, pp. 1083- 1093, 2002.

[22] ALVAREZ, V.A., RUSCEKAITE, R.A., VAZQUEZ, A. "Mechanical properties and water absorption behavior of composites made from a biodegradable matrix and alkaline-treated sisal fibres", Journal Composites Materials, v.37, n.17, pp.1575-1588, 2003.

[23] MOHANTY, S., NAYA, K.S.K., VERMA, S.K., et al., "Effect of MAPP as a coupling agent on the performance of jute-PP composites", Journal of Reinforced Plastics and Composites, v. 23, pp. 625-637, 2004.

[24] SOMBATSOMPOP, N., CHAOCHANCHAIKUL, K."Effect of moisture content on mechanical properties, thermal and structural stability and extrudate texture of poly (vinyl chloride)/wood sawdust composites", Polymer International, v. 53, n.9, pp. 1210-1218, 2004. 